\title{
Functional and metabolic imaging of the right ventricle: short-term caloric restriction increases myocardial triglyceride content and decreases diastolic heart function
}

\author{
Sebastiaan Hammer ${ }^{1 *}$, RW Van Der Meer ${ }^{1}$, Johannes A Romijn², Johannes W Smit ${ }^{2}$, Albert de Roos ${ }^{1}$, \\ Hildo J Lamb ${ }^{1}$
}

From 15th Annual SCMR Scientific Sessions

Orlando, FL, USA. 2-5 February 2012

\section{Background}

Caloric restriction increases plasma non-esterified fatty acid (NEFA) levels, and increases myocardial triglyceride content. It has been shown that elevated levels of NEFA's in patients with metabolic disease (metabolic syndrome/ type 2 diabetes mellitus) are associated with a decrease in left ventricular function. However little is known about its effects on right ventricular function. Therefore, the purpose of the present study was to evaluate myocardial metabolic flexibility in relation to right ventricular diastolic function in healthy volunteers after short-term caloric restriction.

\section{Methods}

Measures were performed in 14 healthy subjects before and after 3 days of caloric restriction based on Modifast diet $(500 \mathrm{kcal} /$ day) using cardiovascular magnetic resonance imaging (MRI). Myocardial triglyceride (TG) content was measured in the interventricular septum using navigator gated, proton MR spectroscopy. After water suppression, myocardial TG content was quantified as a percentage of the unsuppressed water signal. Right ventricular diastolic function was measured using MR velocity mapping across the tricuspid valve. Early (E) deceleration rate was quantified and regarded as representative for right heart diastolic function.

\section{Results}

Caloric restriction increased plasma fatty acid levels from $0.53 \pm 0.30 \mathrm{mmol} / \mathrm{L}$ at baseline to $1.14 \pm$ $0.39 \mathrm{mmol} / \mathrm{L}$ after caloric restriction. Concomitantly, myocardial TG content increased from $0.38 \pm 0.19 \%$ to $0.59 \pm 0.24 \%(\mathrm{P}<0.01)$. These changes were associated with a decrease in right ventricular diastolic function ( $\mathrm{E}$ deceleration rate) from $-1.79 \pm 0.50 \mathrm{ml} / \mathrm{sec} 2 \times 10-3$ to $-1.25 \pm 0.37 \mathrm{ml} / \mathrm{sec} 2 \times 10-3(\mathrm{P}<0.01)$, example is shown in figure 1.

\section{Conclusions}

Short-term caloric restriction in healthy volunteers increases myocardial triglyceride content and is associated with decreased right ventricular filling properties. The underlying pathophysiological mechanism may be involved in the development of global cardiac dysfunction in metabolic disease, such as obesity and diabetes type 2 related diseases.

\section{Funding}

None.

Author details

${ }^{1}$ Radiology, Leiden University Medical Centre, Leiden, Netherlands. 2Endocrinology, Leiden University Medical Centre, Leiden, Netherlands.

Published: 1 February 2012

${ }^{1}$ Radiology, Leiden University Medical Centre, Leiden, Netherlands Full list of author information is available at the end of the article 


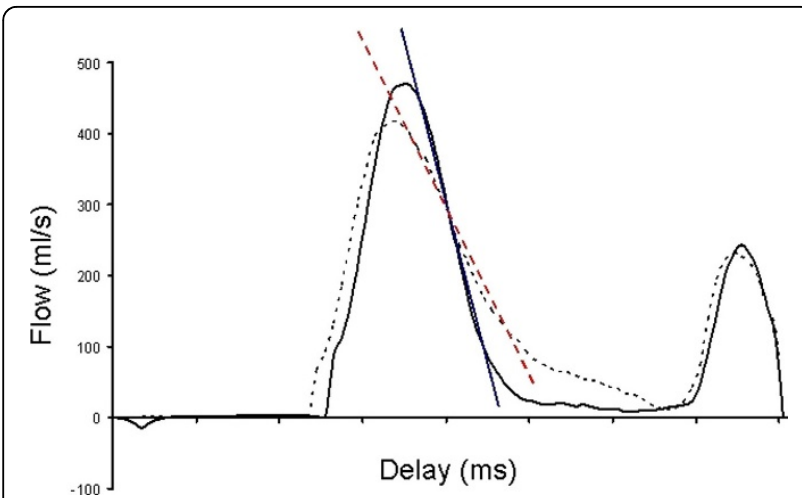

Figure 1 Typical trans-tricuspid flow curve and tangent lines of a subject before (solid lines) and after (dashed lines) caloric restriction, showing a decrease in early deceleration.

doi:10.1186/1532-429X-14-S1-P68

Cite this article as: Hammer et al.: Functional and metabolic imaging of the right ventricle: short-term caloric restriction increases myocardial triglyceride content and decreases diastolic heart function. Journal of Cardiovascular Magnetic Resonance 2012 14(Suppl 1):P68.

Submit your next manuscript to BioMed Central and take full advantage of:

- Convenient online submission

- Thorough peer review

- No space constraints or color figure charges

- Immediate publication on acceptance

- Inclusion in PubMed, CAS, Scopus and Google Scholar

- Research which is freely available for redistribution

Submit your manuscript at www.biomedcentral.com/submit 